\title{
Drying seaweeds using hybrid hot water Goodle dryer (HHGD): comparison with freeze-dryer in chemical composition and antioxidant activity
}

\author{
D. P. Nagahawatta ', K. K. Asanka Sanjeewa', Thilina U. Jayawardena', Hyun-Soo Kim², Hye-Won Yang ${ }^{1}$, \\ Yunfei Jiang ${ }^{1}$, Jun-Geon Je' ${ }^{1}$ Tae-Ki Lee ${ }^{3, *}$, You-Jin Jeon ${ }^{1,4, *}$ \\ ${ }^{1}$ Department of Marine Life Sciences, Jeju National University, Jeju 63243, Korea \\ ${ }^{2}$ Department of Applied Research, National Marine Biodiversity Institute of Korea, Seocheon 33662, Korea \\ ${ }^{3}$ Department of Hotel Cuisine \& Baking, Jeonnam State University, Damyang 57337, Korea \\ ${ }^{4}$ Marine Science Institute, Jeju National University, Jeju 63243, Korea
}

\begin{abstract}
Seaweeds are a potential source of minerals, essential amino acids, fatty acids, proteins, and various bioactive compounds such as antioxidants. The higher water content of seaweeds reduces the shelf life and this requires the appropriate drying method. The drying conditions play a major role in the conservation of nutrient composition in dried seaweeds. In recent years, the seaweed industry has used many different drying methods with advantages and limitations. Hybrid hot-water Goodle dryer (HHGD) which is a special dryer mixed with hot-water and a Korean traditional heating system (Goodlejang) might be a solution to avoid these limitations. The present study evaluated the effect of drying conditions in HHGD on nutrient composition and bioactivities of brown seaweeds. Moreover, freeze-dryer (FD) and HHGD were employed in this study to compare the dried outputs obtained from four brown seaweed species. The present study aims to evaluate the effect of the hybrid hot-water Goodle drying method (HHGDM) on the nutritional composition and antioxidant activity of dried seaweeds. AOAC standard methods were used to analyze the proximate composition of dried samples and their $70 \%$ ethanol extract. The intracellular and extracellular antioxidant activities were evaluated using Vero cells and electron spin resonance (ESR) spectrometer respectively. High performance liquid chromatography, apoptotic body formation, and in-vivo experiments were used for further confirmation of the quality of dried output. The proximate composition results obtained from drying in HHGD and FD did not exhibit any significant difference. Moreover, the seaweed extracts from the dried seaweeds by HHGD and FD dryings were also not different and both significantly down-regulated in-vivo and in-vitro oxidative stress. Furthermore, the high performance liquid chromatography results revealed that the two dryers did not make the major peaks different in the chromatograms. Freeze-drying method (FDM) provides elevated quality for dried output, but there are limitations such as high cost and low capacity. The results from a novel HHGD did not
\end{abstract}

Received: Dec 9, 2020 Revised: Dec 15, 2020 Accepted: Dec 15, 2020

${ }^{*}$ Corresponding author: You-Jin Jeon

Department of Marine Life Sciences, Jeju National University, Jeju 63243, Korea

Tel: +82-64-754-3475, E-mail: youjin2014@gmail.com, ORCID: https://orcid.org/0000-0003-3299-7266

${ }^{*}$ Corresponding author: Tae-Ki Lee

Department of Hotel Cuisine \& Baking, Jeonnam State University, Jeonnam 57337, Korea

Tel: +82-61-380-8668 or +82-61-380-8498, E-mail: tglee@dorip.ac.kr, ORCID: https://orcid.org/0000-0001-7803-4268

This is an Open Access article distributed under the terms of the Creative Commons Attribution Non-Commercial License (http://creativecommons.org/licenses/by$\mathrm{nc} / 4.0 /$ ) which permits unrestricted non-commercial use, distribution, and reproduction in any medium, provided the original work is properly cited.

Copyright $\odot 2021$ The Korean Society of Fisheries and Aquatic Science 
provide any significant difference with the results in FD and expressed a potential to avoid the limitations in FD. Overall, these findings solidified the applicability of HHGD over FD.

Keywords: Hybrid hot-water Goodle dryer, Freeze dryer, Brown seaweeds, Antioxidant activity, Nutritional composition

\section{Introduction}

Seaweeds are considered as a traditional food in Asian countries. Chemical constituents obtained from seaweeds express various biological, functional, and nutritional activities. Terpenoids, flavonoids, essential fatty acids, vitamins, xanthophyll, proteins, and carotenoids are considered as valuable bioactive components in seaweeds (Neoh et al., 2016). Besides, seaweeds provide a plethora of health-promoting nutrients (Matanjun et al., 2009). Based on the previous studies, seaweeds are considered as a comparatively good source of certain vitamins, polysaccharides, and minerals (Darcy-Vrillon, 1993). In the economical stream, brown seaweeds are considered as the most important seaweed group (Chapman \& Chapman, 1980). Moreover, brown seaweeds are abundant in bioactive compounds that can be used as functional ingredients for improving human health. The previous researches have reported their various bioactivities, such as anti-cancer, anti-inflammation, anti-diabetic, and antioxidant (Wijesinghe \& Jeon, 2012). Normally, fresh seaweeds contain a large amount of water. Drying of seaweeds is used to reduce moisture retention and seaweed drying is an important and key step to ensure its nutritional value. Seaweeds that are properly dried can be kept for a long time (Naylor, 1976). Moreover, drying can be considered as an important post-harvest preservation method. However, the drying process causes some deformation of the vegetal and greater or lesser exposure of anti-oxidant compounds (Nguyen et al., 2016). Additionally, enzymatic degradation and microbial growth are down-regulated due to the drying process. Traditional drying techniques express some limitations, such as time-consuming, loss of quality in the plant, and loss of active ingredients (Fennell et al., 2004). The freeze drying method (FDM) is a convenient substitution for avoiding these limitations. FDM uses the dehydration process under low temperatures. Here, sublimation is used to remove ice by lowering the pressure. The quality of the product is high in this technique due to the low temperatures. However, the FDM is considered a comparatively high-cost method on an industrial scale. The cost of FDM is 5 times more than normal conventional drying methods. Further, the cost of energy is also high due to elevated energy consumption to complete the sublimation process (Ratti, 2001). According to the previous studies, the sun drying method has been widely and commonly used for economic reasons, seaweed studies, and phycocolloid industry. The sun-drying method generally expresses nearly similar nutritional quality to the FDM than other traditional drying methods. However, this method also contains limitations comparatively with the FDM such as depending on environmental factors and high labor-intensive (Chan et al., 1997).

On the other hand, recently hybrid hot-water Goodle dryer (HHGD: Korea Patent No. 1559558, 1613666, 1971728, 1935005) has been developed by King Ston located in Buyeo-gun, Chungcheongnam-do, Republic of Korea to avoid the above mentioned limitations. It could express various positive impacts on the seaweed drying process comparatively with other methods such as low cost, low energy consumption, low labor incentive, and ensure the nutrient composition of the seaweeds. HHGD is to use hot-water under the Korean traditional floor heating system (Goodle-Jang) and then this hot-water heats flat stone, which a far infrared irradiation emits from. Consequently, it names a "hybrid hot-water Goodle dryer".

Hence, this paper aims to evaluate the effect of the hybrid hot-water Goodle drying method (HHGDM) on the nutritional composition and antioxidant activity of the selected brown seaweeds to allow the novel pathway for developing new nutraceuticals and functional food ingredients.

\section{Material and Methods}

\section{Chemicals and reagents}

Vero cells were purchased from the Korean cell line bank (KCLB, Seoul, Korea). Roswell Park Memorial Institute Medium (RPMI) and fetal bovine serum (FBS) were purchased from GIBCO (Grand Island, NY, USA). 1,1-Diphenyl-2-picrylhydrazyl (DPPH), 5,5-dimethyl-1-pyrroline $\mathrm{N}$-oxide (DMPO), ferrous sulphate $\left(\mathrm{FeSO}_{4}\right)$, hydrogen peroxide $\left(\mathrm{H}_{2} \mathrm{O}_{2}\right)$, $\alpha$-(4-pyridyl $\mathrm{N}$-oxide)-N-tert-butylnitrone (POBN), 2,2'-azobis(2-methyl- 
propionamidine) dihydrochloride (AAPH), Hoechst 33342, 3-(4,5-dimethylthiazol-2-yl)-2,5-diphenyltetrazolium bromide (MTT), 20,70-20 70-dichlorodihydrofluorescein diacetate (DCFH-DA), and acridine orange, were purchased from Sigma, Aldrich (St. Louis, MO, USA) USA. All the other chemicals used in this study were of high purity grade.

\section{Sample collection}

The seaweed species were collected along the shore of Jeju Island, South Korea from February to March 2019. Seaweeds, Padina arborescens (PA), Sargassum autumnale (SA), Sargassum thunbergii (ST), and Ishige okamurae (IO) were used for drying by HHGDM and FDM. All the samples were washed thoroughly to remove salt, attached epiphytes, and sand.

\section{Drying}

Each chopped seaweed sample was divided into two portions, and HHGDM and FDM were used to dry each portion. The first portion of each seaweed species was frozen in a $-80^{\circ} \mathrm{C}$ freezer for $24 \mathrm{~h}$ and dried in a freeze-drier for 2 days. The second portion of each seaweed species was dried using HHGDM. The conditions are heating temperature $60^{\circ} \mathrm{C}$, inner humidity $12 \%$, carbon mat temperature $70^{\circ} \mathrm{C}$ with running vortex and suction blower.

\section{Ethanol extraction}

HHGDM and FDM samples were ground into fine particles. $200 \mathrm{~g}$ of each subsequent powder was extracted with $2 \mathrm{~L}$ of $70 \%$ ethanol at room temperature under $100 \mathrm{rpm}$ speed shaking. The above-mentioned steps were repeated three times and the resulted solutions were filtered using Whatman No. 4 filter papers (Whatman, Kent, UK), and a rotary evaporator was used to concentrate the subsequent solvents of filtered ethanol-soluble fractions. The solvent-free seaweed extracts were obtained by HHGDM and FDM. DMSO was used to dissolve the ethanolic extracts of seaweeds from HHGDM and FDM.

\section{Chemical composition analysis}

The general composition of seaweeds dried from HHGDM and FDM were analyzed according to the AOAC standard 2005 standards (AOAC Internationa 1, 2005). The ash content of seaweed samples from the two different drying methods were measured by drying in a furnace at $550^{\circ} \mathrm{C}$ for $6 \mathrm{~h}$ (Sanjeewa et al., 2019). Kjeldahl digestion method was used to determine the protein content of seaweed samples from HHGDM and
FDM. The lipid content was measured by the Soxhlet method, hexane with di-ethyl ether were used as the solvent (Soxtec 2050; FOSS Analytical, Hillerød, Denmark) (Kim et al., 2018). For the chemical composition of the $70 \%$ ethanol extract of the seaweed samples from HHGDM and FDM, the crude proteins were measured by a commercially available BCA protein assay kit (Pierce Company, Massachusetts, USA). Bovine serum albumin was used as the standard and each measurement was triplicated. The phenol contents were measured by Folin-Ciocalteu's method. Gallic acid was used as a standard (Chandler \& Dodds, 1983). The Phenol-sulfuric acid method was used to measure the polysaccharide content. Glucose was used as the standard (Kim et al., 2018). The intercellular antioxidant activities of the seaweed extracts were analyzed using three radicals. Sample concentration was $2 \mathrm{mg} / \mathrm{mL}$. Phosphate saline buffer was used as the control. DPPH, alkyl and, hydroxyl radical activities were measured respectively according to the previously reported methods (Nanjo et al., 1996; Hiramoto et al., 1993; Finkelstein et al., 1980). Electron spin resonance (ESR) spectrometer was (JESFA200; Jeol, Tokyo, Japan) used to evaluate the radical scavenging ability of seaweed extracts. The instrument configurations of modulation frequency $100 \mathrm{kHz}$, central filed $3475 \mathrm{G}$, modulation amplitude $2 \mathrm{G}$, gain $6.3 \times 10^{5}$, and temperature 298 K. $5 \mathrm{~mW}, 10 \mathrm{~mW}$, and $1 \mathrm{~mW}$ microwave powers were used to DPPH, alkyl, and hydroxyl respectively.

\section{Cell viability}

The cytotoxicity of the seaweed extracts was determined via MTT assay (Sanjeewa et al., 2017). The cells were seeded with 1 $\times 10^{5}$ cells $/ \mathrm{mL}$ in 96 well plates. The seeded cells were incubated for $24 \mathrm{~h}$. The series of seaweed extract concentrations (12.5 $\mu \mathrm{g} /$ $\mathrm{mL}, 25 \mu \mathrm{g} / \mathrm{mL}, 50 \mu \mathrm{g} / \mathrm{mL}, 100 \mu \mathrm{g} / \mathrm{mL}$, and $200 \mu \mathrm{g} / \mathrm{mL}$ ) were used to treat the cells. Then the cells were treated with MTT solution prepared in PBS after $24 \mathrm{~h}$ and provide an incubation period for make formazan crystals. The formed formazan crystals were dissolved in DMSO. The absorbance was measured by Synergy ${ }^{\text {TM }}$ HT, Vermont, USA, plate reader. The absorbance values were expressed as a mean percentage value relative to controls.

\section{Evaluation of intracellular reactive oxygen species (ROS) scavenging effect}

Three seaweed concentrations were used to evaluate the intracellular antioxidant effect. Vero cells were seeded $\left(1 \times 10^{5}\right.$ cells/ $\mathrm{mL})$ in 96 well plates. Cells were treated with samples after $24 \mathrm{~h}$ incubation period and co-treated with $1 \mathrm{mM} \mathrm{H}_{2} \mathrm{O}_{2}$ and $10 \mathrm{mM}$ 
AAPH. The cell viability was evaluated after $24 \mathrm{~h}$ incubation by MTT assay.

DCFH-DA assay was used to determine the intracellular ROS scavenging ability of the seaweed extracts (Yang et al., 2011). The Vero cells $\left(1 \times 10^{5}\right.$ cells $\left./ \mathrm{mL}\right)$ cultured in 96 well plates were used to treat by samples $(12.5 \mu \mathrm{g} / \mathrm{mL}, 25 \mu \mathrm{g} / \mathrm{mL}$, and $50 \mu \mathrm{g} / \mathrm{mL}$ ) from different drying methods. The sample treated cells were treated with $\mathrm{H}_{2} \mathrm{O}_{2}$ and AAPH (1 mM) and provide 1-3 $\mathrm{h}$ incubation period. DCFH-DA $(25 \mu \mathrm{g} / \mathrm{mL}) 10 \mu \mathrm{L}$ was added to each well and provided another $10 \mathrm{~min}$ incubation period. Synergy HT multi-detection microplate reader (Bioteck, Winooski, VT, USA) was used to measure the fluorescence at an excitation and an emission wavelength of 485 and $530 \mathrm{~nm}$.

\section{Apoptotic body formation}

The apoptotic body formations of Vero cells were characterized using Hoechst 33342 nuclear staining method by staining nuclear fragmentation and chromatin condensation of cells (Lee et al., 2015). The cells were seeded in 24 well culture plates. The seeded cells were treated by seaweed extracts from different drying methods after $24 \mathrm{~h}$ incubation period. The sample treated cells were stimulated by $1 \mathrm{mM} \mathrm{H}_{2} \mathrm{O}_{2}$ after the incubation period. Then each well was treated with $5 \mu \mathrm{L}$ of Hoechst 33342 stain $(10 \mu \mathrm{g} / \mathrm{mL})$ after $24 \mathrm{~h}$ incubation period (Fernando et al., 2018). The fluorescence images were taken after $10 \mathrm{~min}$ incubation by the fluorescence microscope equipped with a Cool SNAP-Pro color digital camera (Olympus, Tokyo, Japan).

\section{High performance liquide chromatography (HPLC) analysis}

The analysis was performed using Semi-preparative $\mathrm{C}_{18}$ (Agilent proshell $120,4 \mu \mathrm{m}, 4.6 \times 100 \mathrm{~mm}$ ) column connected to a 1220 Infinity IILC HPLC system. The system was equipped with a UV/Vis detector. The HPLC grade solvents (Burdick \& Jackson) were used for analysis. Distilled water was used as a mobile phase with $0.01 \%$ TFA (A) and acetonitrile with $0.01 \%$ TFA (B). The temperature of the column was maintained at $35^{\circ} \mathrm{C}$. The gradient elution was performed at 0-30 $\min 69: 31 ; 30-40 \mathrm{~min}$ $0: 100$ with flow rate $0.3 \mathrm{~mL}$ min and the ultraviolet absorbance was detected at $230 \mathrm{~nm}$.

\section{In vivo evaluation of intracellular hydrogen peroxide scavenging activity using zebrafish embryos}

Adult zebrafish were purchased from Seoul Aquarium, Korea. The acrylic tanks were used to maintain zebrafish under controlled environmental conditions (12/ $10 \mathrm{~h}$ light/ dark cycle with $28.5^{\circ} \mathrm{C}$ ). Fish were fed 6 days per week and 3 times per day by live brine shrimps with tetramine flake. The embryos were obtained by natural spawning which was stimulated with lights on conditions and collection was completed within $30 \mathrm{~min}$.

The healthy zebrafish embryos were obtained after 7-9 h post-fertilization (hpf). The selected embryos were transferred to embryo media in 12 well culture plate and periodically monitored. The transferred embryos were treated with $\mathrm{IO}$ from $\mathrm{HH}$ GDM (HHGDM-IO) and FDM (FDM-IO) $(12.5 \mu \mathrm{g} / \mathrm{mL}, 25 \mu \mathrm{g} /$ $\mathrm{mL}$, and $50 \mu \mathrm{g} / \mathrm{mL}$ ) and incubated for $1 \mathrm{~h}$ and stimulated with $5 \mathrm{mM} \mathrm{H}_{2} \mathrm{O}_{2}(24 \mathrm{~h})$ for evaluating the ROS level and cell death using fluorescence dyes.

The heartbeat rate was measured at $48 \mathrm{hpf}$ to evaluate the toxicity of the sample (Choi et al., 2007). The heartbeat rate of both atrium and ventricle contractions within 3 min were measured under the microscope and the average heartbeat rate per min was presented as the final result. Oxidative sensitive fluorescent probe dye, 2, 7-dichlorodihydrofluorescein diacetate (DCFH-DA) $(20 \mu \mathrm{g} / \mathrm{mL})$ was used to analyze the $\mathrm{H}_{2} \mathrm{O}_{2}$ induced ROS generation in zebrafish embryos according to the previously described method with slight modification (Kang et al., 2013). Cellular peroxides cause further oxidation of DCDH-DA to fluorescence compound dichlorofluorescein (DCF) (Rosenkranz et al., 1992). Acridine orange staining $(7 \mu \mathrm{g} / \mathrm{mL})$ was used to detect cell death in live embryos (Kang et al., 2013). The fluorescence images were taken by the fluorescence microscope equipped with a Cool SNAP-Pro color digital camera (Olympus, Tokyo, Japan). The obtained images were quantified by Image $1.49 \mathrm{v}$ (National Institutes of Health, Bethesda, MD, USA).

\section{Statistical analysis}

The data are expressed as the mean \pm SD. The three independent repetitions were conducted for each sample and test. IBM SPSS Statistics with one-way ANOVA were used to analyze the data $p$-value less than $0.05(p<0.05)$ were considered as significant.

\section{Results and Discussion}

The drying of the seaweed is a highly important factor for the marine industry and offers possibilities for isolation, development of compounds, and novel products to consumers. In recent years, the seaweed industry has used many different drying methods with advantages and limitations. The present study reveals that HHGDM is a possible solution to avoid these limitations.

Drying processes make the changes of seaweeds such 
as shrinkage and crispy nature which cause easy grinding to produce the powder. This is useful for further extraction and analysis. The drying method has an impact on nutrient composition and bioactivity of seaweeds, depending on their drying conditions (Kyriakopoulou et al., 2013). In general, several drying methods are used for seaweed dryings such as FDM, sun drying, oven drying, and vacuum drying (Neoh et al., 2016). However, each drying method contains advantages and disadvantages such as cost, capacity, and environmental factors. Therefore, the requirement of the drying method which can ensure the nutritional value of seaweeds after drying with lowcost is an important factor for the industrial sector. HHGDM is a comparatively low-cost method that uses low temperature for drying. This study was conducted to evaluate the quality of the dried seaweeds from HHGDM in proximate compositions and antioxidant activities by comparing with FDM.

The proximate compositions of seaweeds from the two different drying methods were analyzed by AOAC standard method (AOAC International, 2005). The results are summarized in
Table 1 and Table 2. Among the dried seaweeds obtained from the two different drying methods, there was no significant difference in the proximate compositions including lipid, polysaccharide, protein, ash, and moisture content between HHGDM and FDM. Moreover, the yields as well as the contents of proteins, phenols, polysaccharides, sterols for the 70\% ethanol extracts from HHGDM and FDM also did not express any significant difference. The moisture content of the dried samples is an important factor. Hence, the moisture content was used to evaluate the final moisture retention in dried seaweeds. All seaweed samples from HHGDM and FDM were dried until constant weight. The final moisture content of seaweed samples from HHGDM and FDM were $8.98 \%-11.95 \%$ and $8.15 \%-10.96 \%$, respectively. This result reflects HHGDM can effectively remove moisture from the seaweeds like the FDM.

Phenolic compounds are widely accumulated in the cell wall. Moreover, other compounds such as flavonoids and lignin are accumulated in vacuoles. Phenolic compounds express their antioxidant ability due to their redox properties. The preser-

Table 1. Proximate composition of brown seaweeds from HHGDM and FDM

\begin{tabular}{|c|c|c|c|c|c|c|}
\hline Sample name & Drying method & Ash & Moisture & Lipid & Protein & Polysaccharide \\
\hline \multirow[t]{2}{*}{ Padina arborescens } & HHGDM & $13.30 \pm 0.08$ & $8.98 \pm 0.77$ & $5.50 \pm 0.50$ & $15.2 \pm 0.20$ & $54.82 \pm 2.60$ \\
\hline & FDM & $13.63 \pm 0.55$ & $8.21 \pm 0.77$ & $3.80 \pm 0.49$ & $19.09 \pm 0.93$ & $54.62 \pm 3.00$ \\
\hline \multirow[t]{2}{*}{ Sargassum autumnale } & HHGDM & $14.98 \pm 0.11$ & $11.01 \pm 0.79$ & $2.08 \pm 0.51$ & $14.91 \pm 0.17$ & $55.61 \pm 3.20$ \\
\hline & FDM & $14.44 \pm 0.49$ & $9.46 \pm 0.64$ & $2.00 \pm 1.30$ & $15.70 \pm 0.69$ & $55.41 \pm 3.40$ \\
\hline \multirow[t]{2}{*}{ Sargassum thunbergii } & HHGDM & $14.49 \pm 0.05$ & $11.95 \pm 0.86$ & $5.20 \pm 1.30$ & $8.62 \pm 0.29$ & $55.81 \pm 3.40$ \\
\hline & FDM & $15.00 \pm 0.17$ & $10.96 \pm 1.20$ & $5.00 \pm 0.50$ & $9.34 \pm 0.19$ & $55.61 \pm 2.90$ \\
\hline \multirow[t]{2}{*}{ Ishige okamurae } & HHGDM & $16.57 \pm 0.06$ & $9.76 \pm 0.86$ & $4.30 \pm 1.30$ & $11.52 \pm 0.31$ & $56.59 \pm 3.40$ \\
\hline & FDM & $16.43 \pm 0.06$ & $8.15 \pm 0.69$ & $1.40 \pm 0.50$ & $10.46 \pm 0.42$ & $52.20 \pm 3.30$ \\
\hline
\end{tabular}

Experiments were carried out in triplicate, and the results are represented as mean $\pm S D$.

HHGDM, hybrid hot-water Goodle drying method; FDM, freeze drying method.

Table 2. Proximate composition of $70 \%$ ethanol extract from HHGDM and FDM

\begin{tabular}{|c|c|c|c|c|c|c|}
\hline Sample name & Drying method & Yield & Protein & Polyphenol & Polysaccharide & Sterol \\
\hline \multirow[t]{2}{*}{ Padina arborescens } & HHGDM & $8.07 \pm 0.18$ & $3.04 \pm 0.54$ & $6.77 \pm 0.42$ & $2.94 \pm 0.37$ & $5.60 \pm 1.06$ \\
\hline & FDM & $8.23 \pm 0.61$ & $3.82 \pm 0.39$ & $6.57 \pm 0.43$ & $3.29 \pm 0.47$ & $3.95 \pm 0.02$ \\
\hline \multirow[t]{2}{*}{ Sargassum autumnale } & HHGDM & $7.11 \pm 0.95$ & $2.98 \pm 0.42$ & $7.56 \pm 0.51$ & $3.29 \pm 0.38$ & $3.13 \pm 1.13$ \\
\hline & FDM & $8.56 \pm 0.81$ & $3.14 \pm 0.24$ & $7.36 \pm 0.69$ & $3.47 \pm 0.22$ & $3.95 \pm 1.16$ \\
\hline \multirow[t]{2}{*}{ Sargassum thunbergii } & HHGDM & $8.61 \pm 0.25$ & $1.72 \pm 0.27$ & $7.76 \pm 0.69$ & $3.12 \pm 0.61$ & $5.01 \pm 1.12$ \\
\hline & FDM & $8.33 \pm 0.69$ & $1.87 \pm 0.59$ & $7.56 \pm 0.41$ & $3.29 \pm 0.39$ & $4.35 \pm 1.16$ \\
\hline \multirow[t]{2}{*}{ Ishige okamurae } & HHGDM & $8.53 \pm 0.72$ & $2.30 \pm 0.65$ & $8.54 \pm 0.68$ & $2.24 \pm 0.38$ & $4.78 \pm 1.33$ \\
\hline & FDM & $7.17 \pm 0.81$ & $2.09 \pm 0.72$ & $8.15 \pm 0.72$ & $2.99 \pm 0.86$ & $2.31 \pm 1.14$ \\
\hline
\end{tabular}

Experiments were carried out in triplicate, and the results are represented as mean $\pm S D$.

HHGDM, hybrid hot-water Goodle drying method; FDM, freeze drying method. 
vation of phenolic compounds is based on drying conditions (Chan et al., 2015). According to the results of Table 1, the phenolic content of dried seaweed from HHGDM was conserved without any significant difference with FDM. Moreover, this reflects the drying conditions of HHGDM do not express the negative effect on the phenolic content comparatively FDM. Antioxidants are substances that can significantly delay or inhibit the oxidation of the substrate even present in a low concentration compared to the oxidizable substrate (Halliwell \& Gutteridge, 1985). Free radical scavengers are considered as antioxidants that are capable to scavenge ROS. These ROS cause modifications of lipids, proteins, and DNA that cause various diseases such as arthritis, diabetes, pulmonary dysfunction, and inflammatory disorders (Frölich \& Riederer, 1995). The different levels of oxidative sequence can be affected by antioxidants. Moreover, antioxidants can inhibit free radical chain reaction by delaying the free radical formation or competing with existing radicals and removing those radicals from the reaction medium (Winata \& Lorenz, 1996). Brown seaweeds contain numerous bioactive compounds such as phenolic compounds that exhibit antioxidant activities (Wijesinghe \& Jeon, 2012). Therefore, drying conditions are important to conserve the antioxidant ability of the dried seaweed. Table 3 shows the primary screening results of the intercellular antioxidant ability of the $70 \%$ ethanol extracts. In the present study, DPPH, alkyl, and hydroxyl radicals
Table 3. Radical scavenging antioxidant activities of $70 \%$ ethanol extracts of seaweeds from HHGDM and FDM

\begin{tabular}{lllll}
\hline \multirow{2}{*}{ Sample name } & Drying & \multicolumn{3}{l}{$\mathrm{IC}_{50}$ values for radical scavenging activity $(\mu \mathrm{g} / \mathrm{ml})$} \\
\cline { 3 - 5 } & method & DPPH & Alkyl & Hydroxyl \\
\hline Padina & HHGDM & $585.15 \pm 3.86$ & $245.89 \pm 12.3$ & $211.63 \pm 6.55$ \\
arborescens & FDM & $628.84 \pm 21.40$ & $280.62 \pm 20.05$ & $232.45 \pm 6.12$ \\
Sargassum & HHGDM & $178 \pm 8.14$ & $181.00 \pm 1.36$ & $159.69 \pm 4.33$ \\
autumnale & FDM & $227.28 \pm 1.81$ & $183.51 \pm 1.43$ & $162.57 \pm 5.56$ \\
Sargassum & HHGDM & $83.6 \pm 3.24$ & $120.72 \pm 12.68$ & $99.54 \pm 4.74$ \\
thunbergii & FDM & $92.87 \pm 4.74$ & $150.01 \pm 4.53$ & $112.22 \pm 5.45$ \\
Ishige & HHGDM & $28.14 \pm 2.85$ & $63.76 \pm 8.46$ & $52.45 \pm 2.34$ \\
okamurae & FDM & $33.74 \pm 0.96$ & $95.26 \pm 4.59$ & $83.12 \pm 3.21$ \\
\hline
\end{tabular}

Experiments were carried out in triplicate, and the results are represented as mean $\pm S D$. HHGDM, hybrid hot-water Goodle drying method; FDM, freeze drying method; $\mathrm{DPPH}$, 1,1-diphenyl-2-picrylhydrazyl.

were used to evaluate the antioxidant ability of four brown seaweed extracts. Moreover, the $\mathrm{IC}_{50}$ values of the seaweed extracts between HHGDM and FDM did not express any significant difference. According to the results, IO recorded the highest $\mathrm{DPPH}$, alkyl, and hydroxyl radical scavenging activity.

The cytotoxicity of the seaweed extracts was evaluated in Vero cells using MTT assay (Fig. 1). The five concentrations (12.5 $\mu \mathrm{g} / \mathrm{mL}-200 \mu \mathrm{g} / \mathrm{mL}$ ) were used to determine the cytotoxicity. According to the results, three concentrations did not express significant down-regulation of cell viability. Therefore, $12.5 \mu \mathrm{g} /$

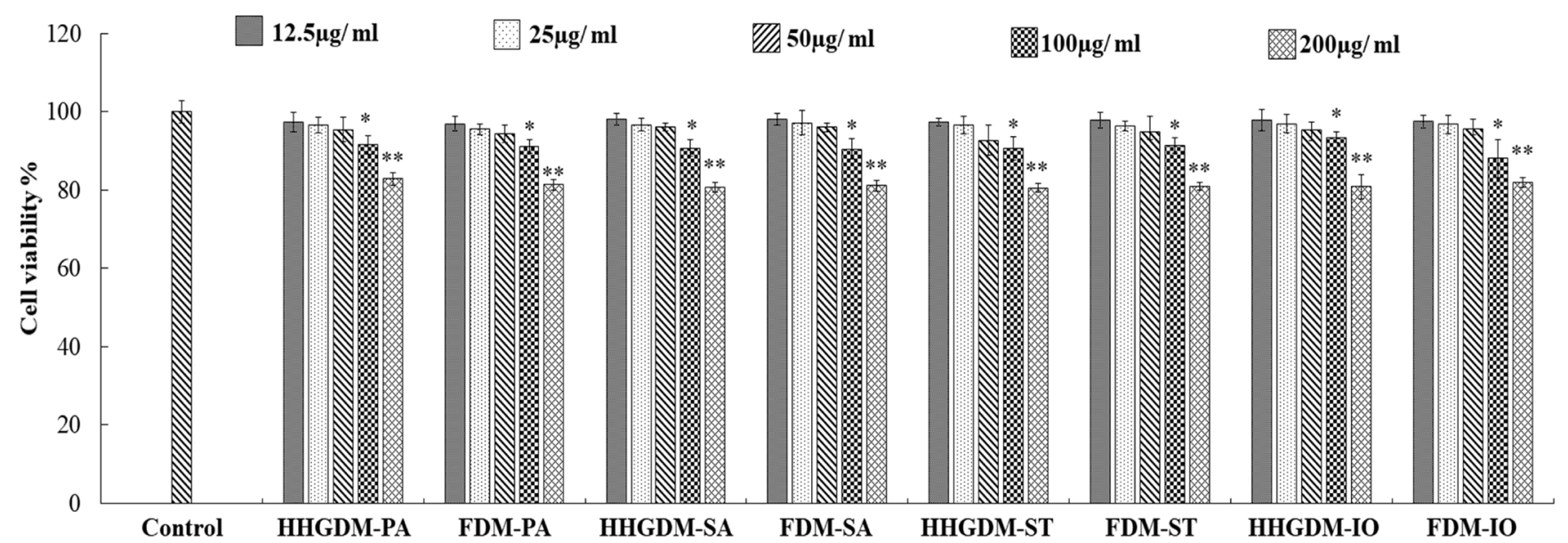

Fig. 1. Cytotoxicity effect of $70 \%$ ethanol extract of seaweeds from HHGDM and FDMM in Vero cells. Cells were seeded $\left(1 \times 10^{5}\right.$ cells $/ \mathrm{mL}$ ) and treated with different concentrations of the samples. Following a $24 \mathrm{~h}$ incubation period, the cell viability was measured by MTT assay. Experiments were carried out in triplicate, and the results are represented as mean \pm SD. Values are significantly different from the control group at ${ }^{*} p<0.05$ and ${ }^{* *} p<0.001$. HHGDM, hybrid hot-water Goodle drying method; FDM, freeze drying method; PA, Padina arborescens; SA, Sargassum autumnale; ST, Sargassum thunbergii; IO, Ishige okamurae. 
$\mathrm{mL}-50 \mu \mathrm{g} / \mathrm{mL}$ concentrations were selected for consecutive study. The Vero cells were stimulated with $1 \mathrm{mM} \mathrm{H}_{2} \mathrm{O}_{2}$ and 10 mM AAPH to evaluate the intracellular antioxidant activity of the seaweed extracts. The MTT results of the seaweed extracts from HHGDM expressed a significant and dose-dependent up-regulation in cell viability than the positive control groups. Moreover, these results did not express any significant difference with FDM. These results implied that the extract from dried IO seaweed obtained by HHGGM exhibited strong intracellular antioxidant activities and it was further confirmed that drying conditions do not negatively effect on nutrient composition of seaweed (Fig. 2).

DCFH-DA assay was used to analyze the ROS scavenging ability of the $70 \%$ ethanol extracts of seaweeds (Fig. 3). Cells absorb DCFH-DA and cellular esterases convert DCFH-DA into non-fluorescent DCFH. The intracellular ROS and other peroxides convert non-fluorescent DCFH into fluorescent DCF that can be detected under an excitation wavelength of $485 \mathrm{~nm}$
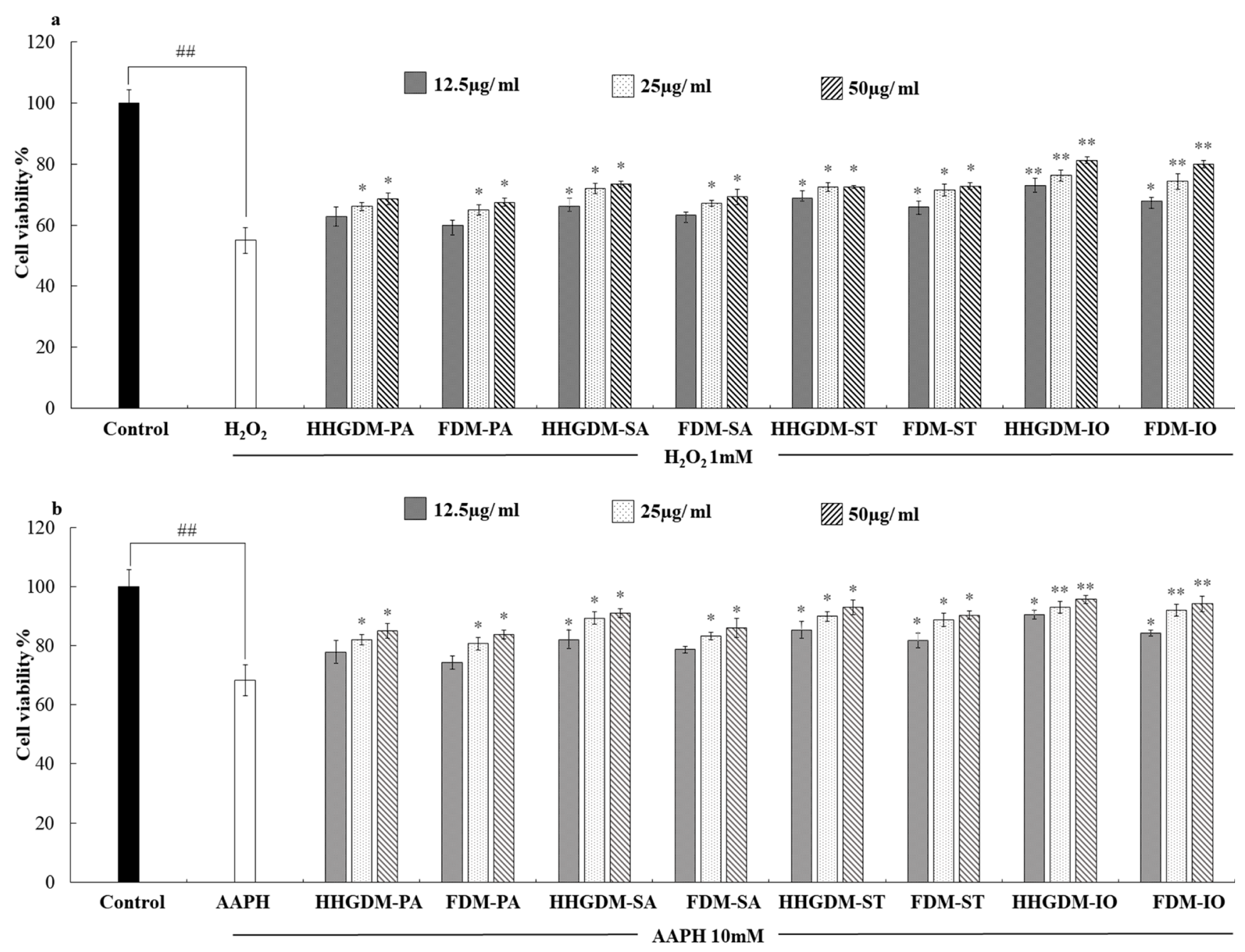

Fig. 2. Intracellular antioxidant effect of $70 \%$ ethanol extract of seaweeds from HHGDM and FDM against (a) $\mathrm{H}_{2} \mathrm{O}_{2}(1 \mathrm{mM})$ and (b) AAPH (10 mM) stimulated Vero cells. Cells were seeded $\left(1 \times 10^{5} \mathrm{cells} / \mathrm{mL}\right)$ and treated with different concentrations of the samples and co-treated with $\mathrm{H}_{2} \mathrm{O}_{2}$ and AAPH. Following an incubation period, the cell viability was measured by MTT assay. Experiments were carried out in triplicate, and the results are represented as mean \pm SD. Values are significantly different from the positive control $\left(\mathrm{H}_{2} \mathrm{O}_{2}\right.$ and AAPH) treated group at ${ }^{*} p<0.05$ and ${ }^{* *} p<0.001$. AAPH, 2,2'-azobis(2-methylpropionamidine) dihydrochloride; HHGDM, hybrid hot-water Goodle drying method; FDM, freeze drying method; PA, Padina arborescens; SA, Sargassum autumnale; ST, Sargassum thunbergii; IO, Ishige okamurae. 

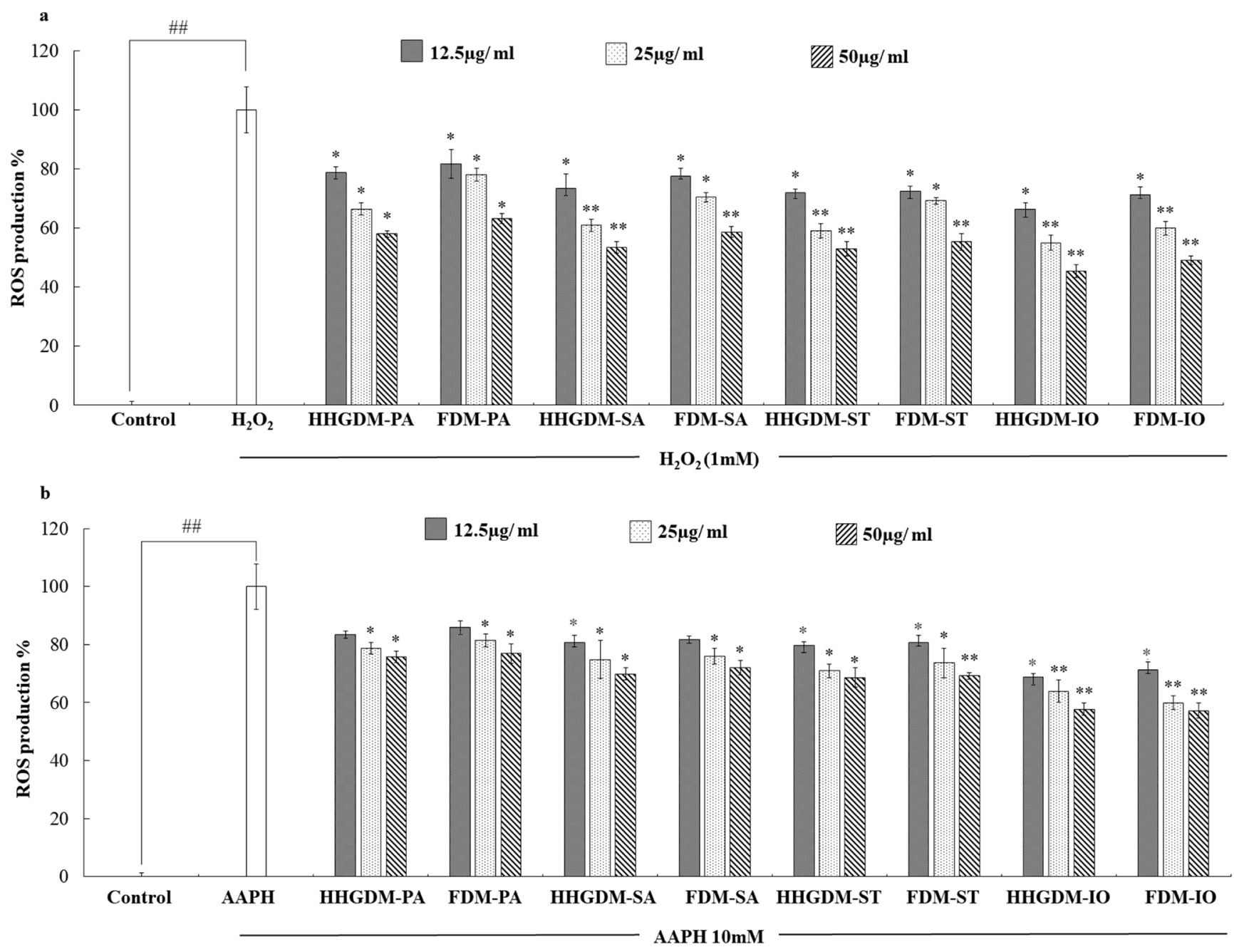

Fig. 3. Intracellular ROS scavenging activities of the samples. Cells were seeded $\left(1 \times 10^{5}\right.$ cells $\left./ \mathrm{mL}\right)$ and treated with different concentrations of the samples and co-treated with (a) $\mathrm{H}_{2} \mathrm{O}_{2}$ and (b) AAPH. Following incubation period, the intracellular ROS levels were determined by DCFH-DA assay. Experiments were carried out in triplicate, and the results are represented as mean \pm SD. Values are significantly different from the positive control $\left(1 \mathrm{mM} \mathrm{H}_{2} \mathrm{O}_{2}\right.$ and $\left.10 \mathrm{mM} \mathrm{AAPH}\right)$ treated group at ${ }^{*} p<0.05$ and ${ }^{* *} p<0.001$. ROS, reactive oxygen species; AAPH, 2,2'-azobis(2-methylpropionamidine) dihydrochloride; HHGDM, hybrid hot-water Goodle drying method; FDM, freeze drying method; PA, Padina arborescens; SA, Sargassum autumnale; ST, Sargassum thunbergii; IO, Ishige okamurae.

and an emission wavelength of $530 \mathrm{~nm}$ (Rastogi et al., 2010). According to the results, the ROS scavenging activities of the seaweed extracts from HHGDM expressed a significant ROS scavenging ability in a dose-dependent manner and there was no significant difference when comparing to FDM. Interestingly, IO indicated elevated results in each parameter than other sea weeds, because of that, $\mathrm{IO}$ was selected for further studies.

HHGDM-IO and FDM-IO were used to analyze the regulation of apoptotic body formation. The apoptotic bodies were visualized using Hoechst 33342 fluorescent dye. The apoptotic bodies are determined based on the nuclear morphology of the cells. Nuclei which are homogeneously stained consider as viable cells. The chromatin condensations or fragmentations are considered as apoptosis (Ahn et al., 2015). According to the results, HHGDM-IO significantly and dose-dependently reduced the apoptotic body formation (Fig. 4). Moreover, there are no significant differences between HHGDM-IO and FDM-IO in the down-regulation of apoptotic body formation. The zebrafish experiments were performed as an in-vivo model for further evaluations and comparison between the two different drying 


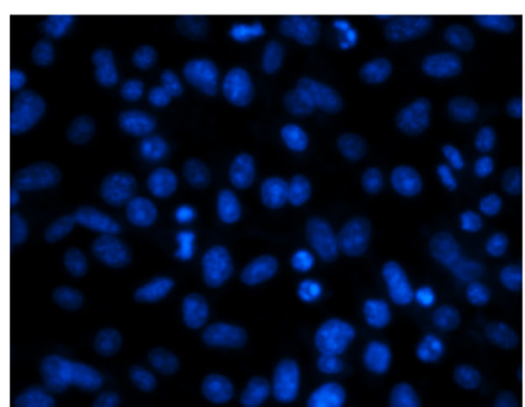

Control

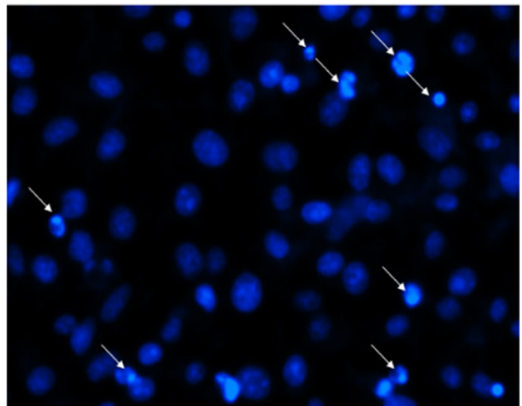

HHGDM-IO $12.5 \mu \mathrm{g} / \mathrm{ml}+\mathrm{H}_{2} \mathrm{O}_{2}(1 \mathrm{mM})$

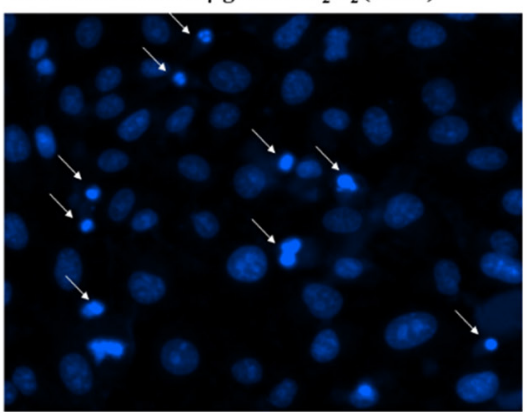

FDM-IO $12.5 \mu \mathrm{g} / \mathrm{ml}+\mathrm{H}_{2} \mathrm{O}_{2}(1 \mathrm{mM})$

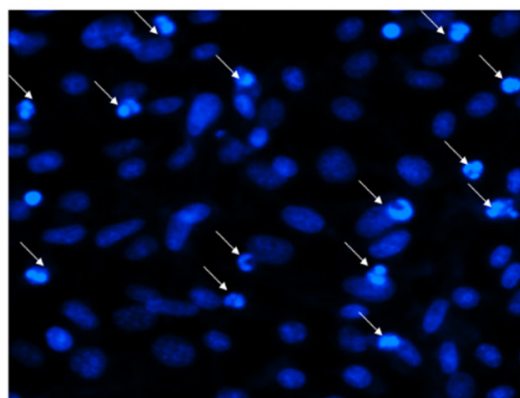

$\mathrm{H}_{2} \mathrm{O}_{2}(1 \mathrm{mM})$

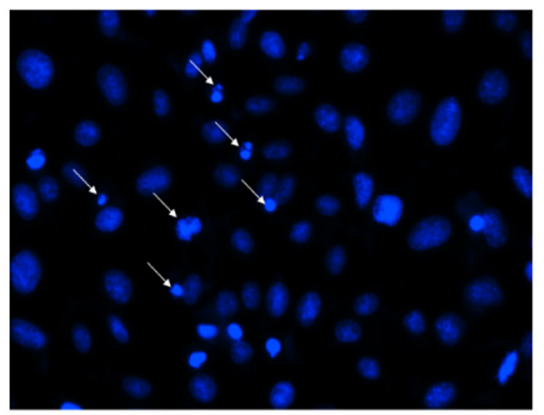

HHGDM-IO $25 \mu \mathrm{g} / \mathrm{ml}+\mathrm{H}_{2} \mathrm{O}_{2}(1 \mathrm{mM})$

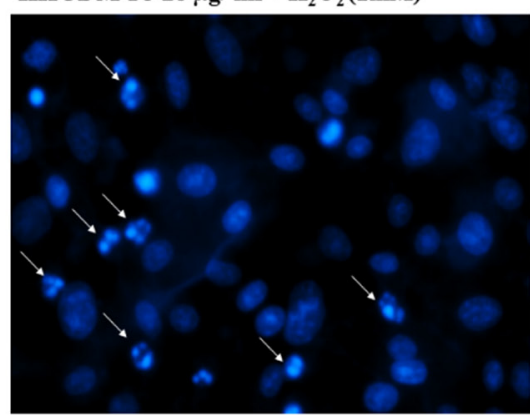

FDM-IO $25 \mu \mathrm{g} / \mathrm{ml}+\mathrm{H}_{2} \mathrm{O}_{2}(1 \mathrm{mM})$
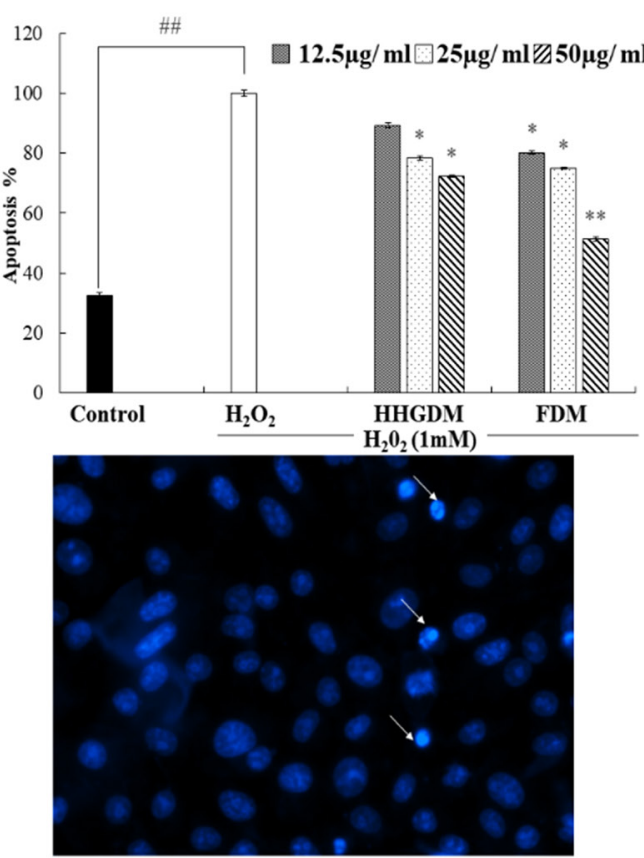

HHGDM-IO $50 \mu \mathrm{g} / \mathrm{ml}+\mathrm{H}_{2} \mathrm{O}_{2}(1 \mathrm{mM})$

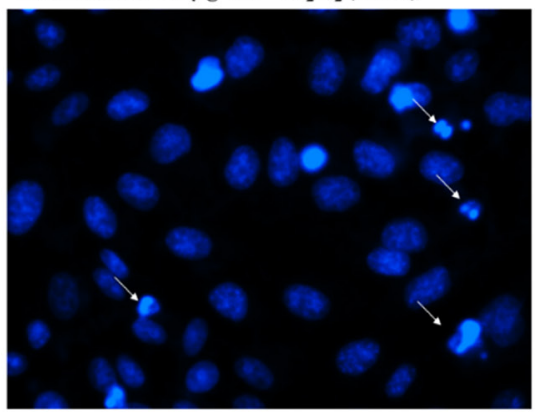

FDM-IO $50 \mu \mathrm{g} / \mathrm{ml}+\mathrm{H}_{2} \mathrm{O}_{2}(1 \mathrm{mM})$

Fig. 4. Evaluating nuclear morphology of Vero cells. Vero cells were treated with different concentrations of HHGDM-IO and FDM-IO methods and co-treated with $\mathrm{H}_{2} \mathrm{O}_{2}(1 \mathrm{mM})$. It was incubated for $24 \mathrm{~h}$ period. Hoechst 33342 was used to stain the nuclear material. Fluorescence images were taken after $10 \mathrm{~min}$ of incubation. Apoptotic body formation results were quantified using ImageJ software. Results are expressed as the mean \pm SD of three separate experiments. Values are significantly different from the positive control $\left(\mathrm{H}_{2} \mathrm{O}_{2}\right)$ treated group at ${ }^{*} p<0.05$ and ${ }^{* *} p<0.001$. HHGDM, hybrid hot-water Goodle drying method; IO, Ishige okamurae; FDM, freeze drying method.

methods with IO extracts. The survival rate of zebrafish was significantly down-regulated than control after exposure to $10 \mathrm{mM}$ $\mathrm{H}_{2} \mathrm{O}_{2}$. The survival rate was $56.07 \%$ on the $5^{\text {th }}$ day after treating $\mathrm{H}_{2} \mathrm{O}_{2}$. However, zebrafish, pre-treated with HHGDM-IO showed a dose-dependent and a significant up-regulation of the survival rate than the $\mathrm{H}_{2} \mathrm{O}_{2}$ treated group. The heart beating rates of zebrafish exposed to $10 \mathrm{mM} \mathrm{H}_{2} \mathrm{O}_{2}$ were significantly increased than the control. Moreover, the elevated heart beating rate was down-regulated by the treatment of HHGDM-IO in a dose-dependent manner (Fig. 5). Acridine orange staining method was used to evaluate the cell death of zebrafish caused by $\mathrm{H}_{2} \mathrm{O}_{2}$ oxidative stress. The up-regulated cell death in zebrafish which was exposed to $\mathrm{H}_{2} \mathrm{O}_{2}$ was declined by seaweed extract treatments. DCFH-DA staining method was used to determine the intracellular ROS levels. The up-regulated ROS level with $\mathrm{H}_{2} \mathrm{O}_{2}$ was declined by HHGDM-IO significantly. Moreover, the interesting factor was no significant difference in the above results between HHGDM-IO and FDM-IO (Fig. 6). In the HPLC analysis, the $70 \%$ ethanol extracts obtained from the IO seaweed dried by HHGDM and FDM showed a similar main peak 

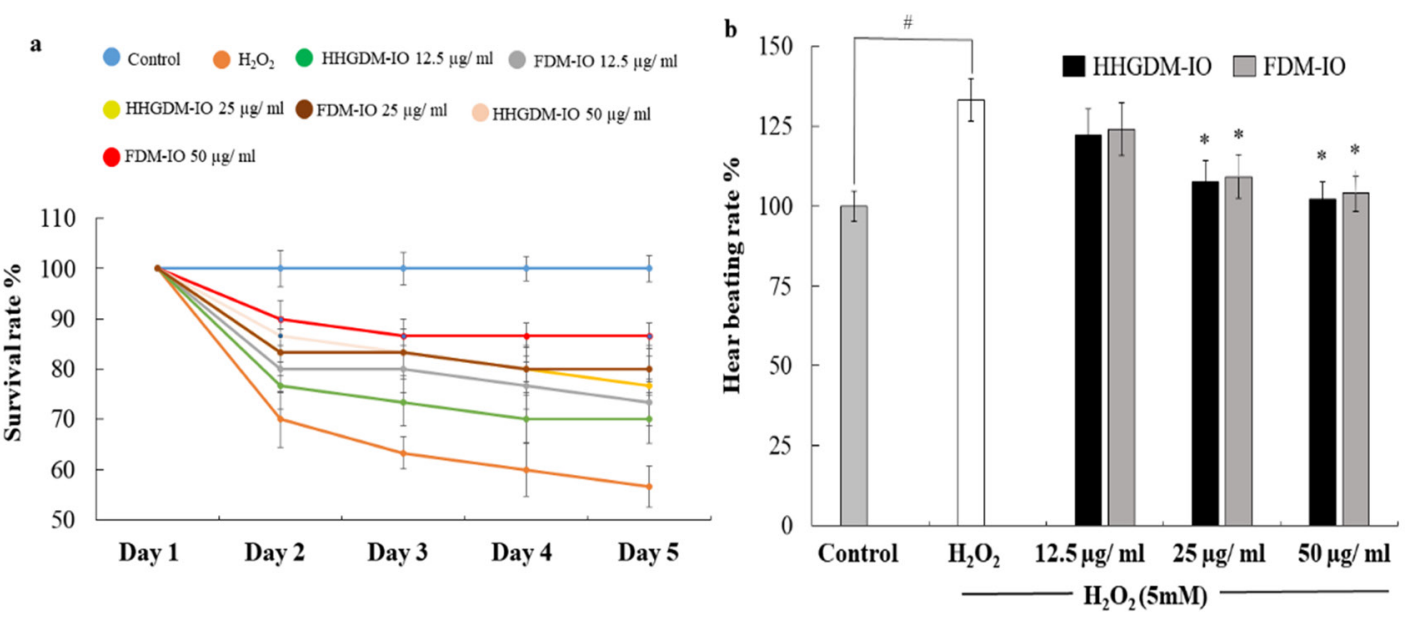

Fig. 5. Evaluation of the protective effect of HHGDM-IO and FDM-IO in $\mathrm{H}_{2} \mathrm{O}_{2}$ induced zebrafish embryo (a) survival \% and (b) heart beating rate. HHGDM, hybrid hot-water Goodle drying method; IO, Ishige okamurae; FDM, freeze drying method.
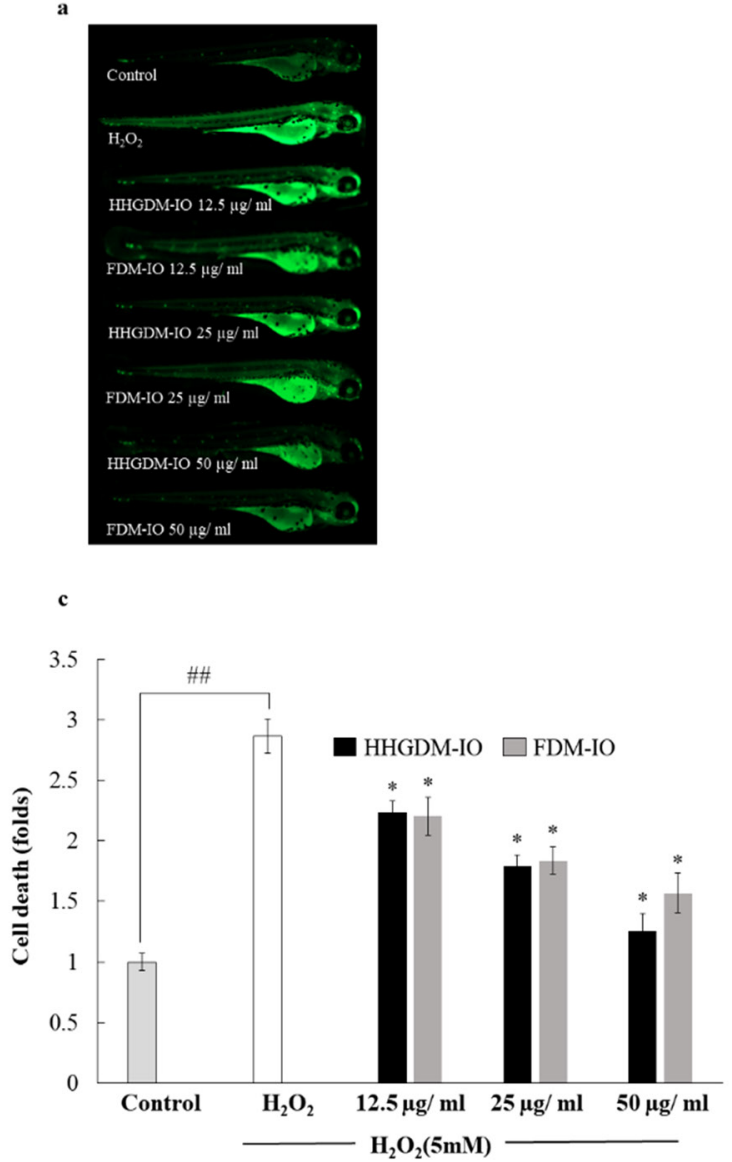

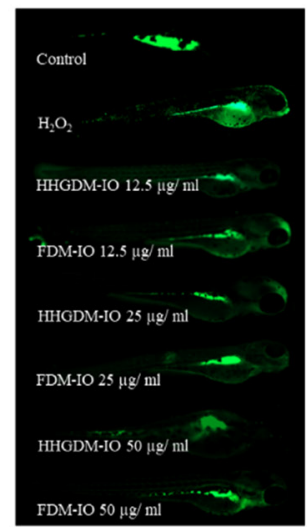

d

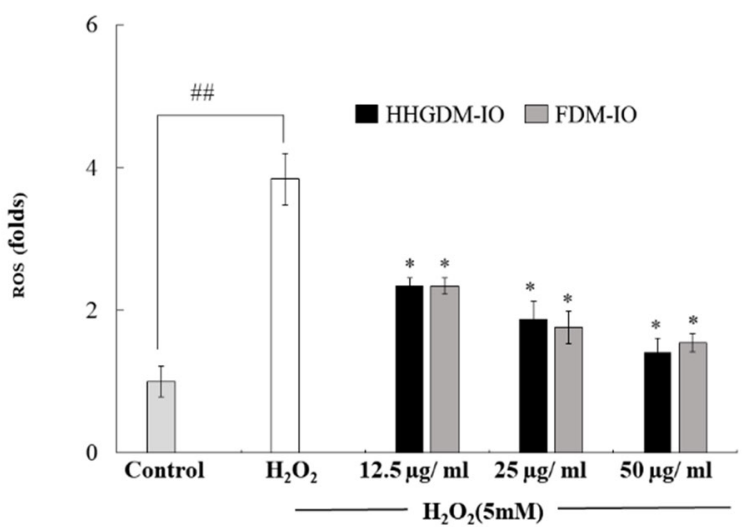

Fig. 6. HHGDM-IO and FDM-IO protect zebrafish embryos against $\mathrm{H}_{2} \mathrm{O}_{2}$ induced cell death (a \& c) and oxidative stress (b \& d). Acridine orange and DCFH-DA staining were used to evaluate cell death and ROS production levels respectively. Individual zebrafish intensity was quantified using image J program. Experiments were performed in triplicate and the data are expressed as mean $\pm{ }^{*} p<$ 0.05 and ${ }^{* * *} p<0.001$. HHGDM, hybrid hot-water Goodle drying method; IO, Ishige okamurae; FDM, freeze drying method; ROS, reactive oxygen species. 
of diphlorethohydroxycarmalol (DPHC) and Ishophloroglucin A (IPA) according to the results, a peak with $10.5 \mathrm{~min}$ and 24.04 min retention time. It was observed that the major active compounds showed no significant difference between HHGDM-IO and FDM-IO (Fig. 7). This reveals that HHGDM could be a suitable drying method for ensuring the nutrient composition of seaweed. As a low-cost drying method, HHGDM expressed a minimum effect on the nutrient composition of dried seaweeds. This leads to the conservation of biological activities in dried samples such as antioxidant activity. The dried output of $\mathrm{HH}$ GDM did not show a toxic effect on cell-based experiments and the yield also wasn't expressed a significant difference from the FDM. The considering factors reveal the potential of this method at the industrial level.

\section{Conclusion}

General composition results of the dried brown seaweeds and their $70 \%$ ethanol extracts between HHGDM and FDM re- vealed no difference in all the tests and bioassay evaluations. This reflects the drying method with HHGDM does not contain adverse effects on the nutritional composition of dried seaweeds. Moreover, these results were supported by intracellular and intercellular ROS scavenging activities, down-regulation of apoptotic body formation, in-vivo experiment, and HPLC analysis results. The FDM provides better nutritional quality to seaweeds, but the operating cost is higher and the drying capacity is lower than the other methods such as sun drying. However, the sun-drying method also depends on weather conditions, day lengths, and high intensive labor. From the results, HHGDM could be an alternative drying technique with a lower cost, lower labor but preserving valuable nutrients. Moreover, HHGDM appears to be the most appropriate drying method in industrial-scale productions.

\section{Competing interests}

No potential conflict of interest relevant to this article was reported.

a

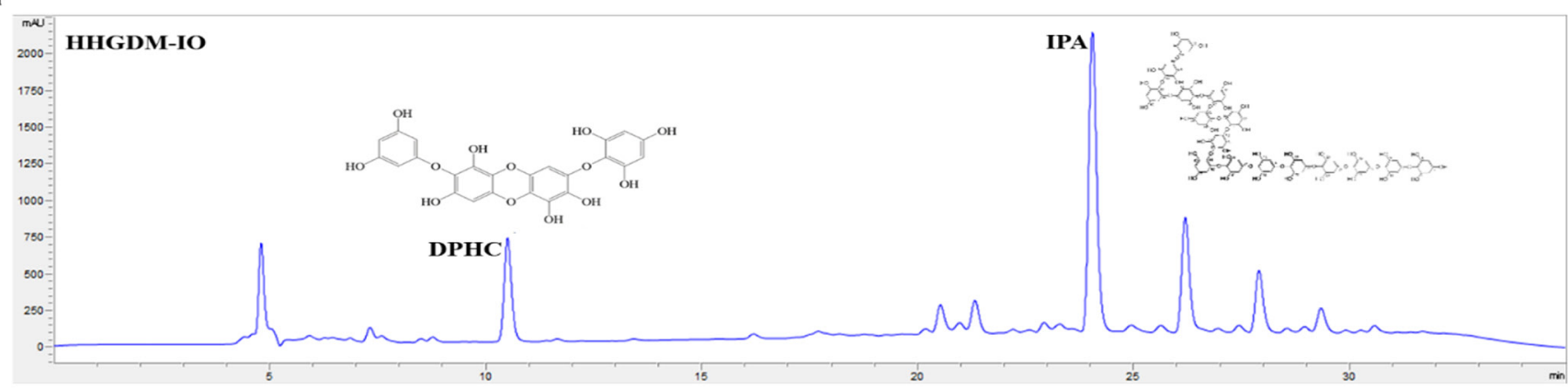

b

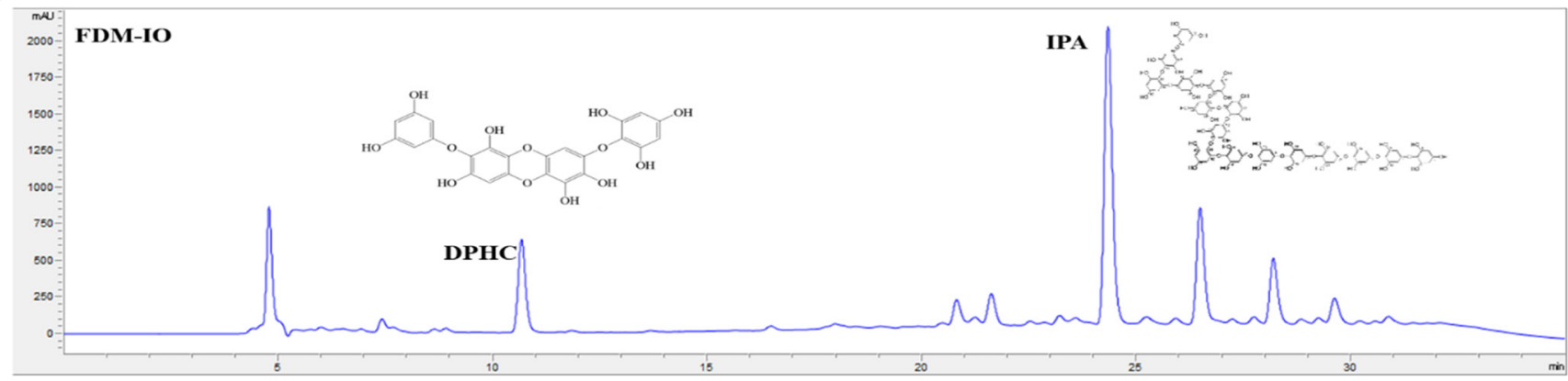

Fig. 7. HPLC analysis of HHGDM-IO and FDM-IO. Samples were prepared at a $5 \mathrm{mg} / \mathrm{mL}$ concentration and resolved by reveres phase HPLC column. The analysis was done using a UV/vis detector. (a) DPHC and IPA from HHGDM-IO and (b) DPHC and IPA from FDM-IO. Diphlorethohydroxycarmalol (DPHC), Ishophloroglucin A (IPA). HPLC, high performance liquide chromatography; HHGDM, hybrid hot-water Goodle drying method; IO, Ishige okamurae; FDM, freeze drying method. 


\section{Funding sources}

King Ston located in Buy-eo-gun, Chungcheongnam-do, Republic of Korea supported this study.

\section{Acknowledgements}

Not applicable.

\section{Availability of data and materials}

Upon reasonable request, the datasets of this study can be available from the corresponding author.

\section{Ethics approval and consent to participate}

The zebrafish experiment received approval from the Animal Care Use Committee of Jeju National University (Approval No. 2017-0001).

\section{References}

Ahn G, Lee WW, Kim KN, Lee JH, Heo SJ, Kang N, et al. A sulfated polysaccharide of Ecklonia cava inhibits the growth of colon cancer cells by inducing apoptosis. EXCLI J. 2015;14:294-306.

AOAC [Association of Official Analytical Chemists] International. Official methods of analysis of AOAC International. 18th ed. Gaithersburg, MD: AOAC International; 2005.

Chan JCC, Cheung PCK, Ang PO. Comparative studies on the effect of three drying methods on the nutritional composition of seaweed Sargassum hemiphyllum (Turn.) C. Ag. J Agric Food Chem. 1997;45:3056-9.

Chan PT, Matanjun P, Yasir SM, Tan TS. Antioxidant activities and polyphenolics of various solvent extracts of red seaweed, Gracilaria changii. J Appl Phycol. 2015;27:2377-86.

Chandler SF, Dodds JH. The effect of phosphate, nitrogen and sucrose on the production of phenolics and solasodine in callus cultures of Solanum laciniatum. Plant Cell Rep. 1983;2:205-8.

Chapman VJ, Chapman DJ. Sea vegetables (algae as food for man). In: Chapman VJ, Chapman DJ, editors. Seaweeds and their uses. Dordrecht: Springer; 1980. p. 62-97.

Choi TY, Kim JH, Ko DH, Kim CH, Hwang JS, Ahn S, et al. Zebrafish as a new model for phenotype-based screening of melanogenic regulatory compounds. Pigment Cell Res. 2007;20:120-7.

Darcy-Vrillon B. Nutritional aspects of the developing use of marine macroalgae for the human food industry. Int J Food Scie Nutr. 1993;44:S23-35

Fennell CW, Light ME, Sparg SG, Stafford GI, van Staden J. Assessing African medicinal plants for efficacy and safety: agricultural and storage practices. J Ethnopharmacol. 2004;95:113-21.

Fernando IPS, Sanjeewa KKA, Kim HS, Wang L, Lee WW, Jeon YJ. Apoptotic and antiproliferative properties of $3 \beta$-hydroxy- $\Delta 5$-steroidal congeners from a partially purified column fraction of Dendronephthya gigantea against HL60 and MCF-7 cancer cells. J Appl Toxicol. 2018;38:527-36.

Finkelstein E, Rosen GM, Rauckman EJ. Spin trapping of superoxide and hydroxyl radical: practical aspects. Arch Biochem Biophys. 1980;200:1-16.

Frölich L, Riederer P. Free radical mechanisms in dementia of Alzheimer type and the potential for antioxidative treatment. Arzneimittelforschung. 1995;45:443-6.

Halliwell B, Gutteridge JMC. Free radicals in biology and medicine. J Free Radic Biol Med. 1985;1:331-2.

Hiramoto K, Johkoh H, Sako KI, Kikugawa K. DNA breaking activity of the carbon-centered radical generated from 2,2'-azobis (2-amidinopropane) hydrochloride (AAPH). Free Radic Res Commun. 1993;19:323-32.

Kang MC, Cha SH, Wijesinghe WAJP, Kang SM, Lee SH, Kim EA, et al. Protective effect of marine algae phlorotannins against AAPH-induced oxidative stress in zebrafish embryo. Food Chem. 2013;138:950-5.

Kim HS, Sanjeewa KKA, Fernando IPS, Ryu B, Yang HW, Ahn G, et al. A comparative study of Sargassum horneri Korea and China strains collected along the coast of Jeju Island South Korea: its components and bioactive properties. Algae. 2018;33:341-9.

Kyriakopoulou K, Pappa A, Krokida M, Detsi A, Kefalas P. Effects of drying and extraction methods on the quality and antioxidant activity of sea buckthorn (Hippophae rhamnoides) berries and leaves. Dry Technol. 2013;31:1063-76.

Lee SH, Kang SM, Sok CH, Hong JT, Oh JY, Jeon YJ. Cellular activities and docking studies of eckol isolated from Ecklonia cava (Laminariales, Phaeophyceae) as potential tyrosinase inhibitor. Algae. 2015;30:163-70.

Matanjun P, Mohamed S, Mustapha NM, Muhammad K. Nutrient content of tropical edible seaweeds, Eucheuma cottonii, Caulerpa lentillifera and Sargassum polycystum. J Appl Phycol. 2009;21:75-80.

Nanjo F, Goto K, Seto R, Suzuki M, Sakai M, Hara Y. Scaveng- 
ing effects of tea catechins and their derivatives on 1,1-diphenyl-2-picrylhydrazyl radical. Free Radic Biol Med. 1996;21:895-902.

Naylor J. Production, trade and utilization of seaweeds and seaweed products. Rome: Food and Agriculture Organization of the United Nations; 1976. p. 159.

Neoh YY, Matanjun P, Lee JS. Comparative study of drying methods on chemical constituents of Malaysian red seaweed. Dry Technol. 2016;34:1745-51.

Nguyen VT, Pham NMQ, Vuong QV, Bowyer MC, van Altena IA, Scarlett CJ. Phytochemical retention and antioxidant capacity of xao tam phan (Paramignya trimera) root as prepared by different drying methods. Dry Technol. 2016;34:324-34.

Rastogi RP, Singh SP, Häder DP, Sinha RP. Detection of reactive oxygen species (ROS) by the oxidant-sensing probe 2,7'-dichlorodihydrofluorescein diacetate in the cyanobacterium Anabaena variabilis PCC 7937. Biochem Biophys Res Commun. 2010;397:603-7.

Ratti C. Hot air and freeze-drying of high-value foods: a review. J Food Eng. 2001;49:311-9.

Rosenkranz AR, Schmaldienst S, Stuhlmeier KM, Chen W, Knapp W, Zlabinger GJ. A microplate assay for the detection of oxidative products using 2',7'-dichlorofluorescin-diacetate. J Immunol Methods. 1992;156:39-45.

Sanjeewa KKA, Fernando IPS, Kim EA, Ahn G, Jee Y, Jeon YJ. Anti-inflammatory activity of a sulfated polysaccharide isolated from an enzymatic digest of brown seaweed Sargassum horneri in RAW 264.7 cells. Nutr Res pract. 2017;11:310.

Sanjeewa KKA, Fernando IPS, Kim SY, Kim WS, Ahn G, Jee Y, et al. Ecklonia cava (Laminariales) and Sargassum horneri (Fucales) synergistically inhibit the lipopolysaccharide-induced inflammation via blocking NF- $\mathrm{BB}$ and MAPK pathways. Algae. 2019;34:45-56.

Wijesinghe WA, Jeon YJ. Enzyme-assistant extraction (EAE) of bioactive components: a useful approach for recovery of industrially important metabolites from seaweeds: a review. Fitoterapia. 2012;83:6-12.

Winata A, Lorenz K. Antioxidant potential of 5-n-pentadecylresorcinol. J Food Proc Preserv. 1996;20:417-29.

Yang X, Kang MC, Lee KW, Kang SM, Lee WW, Jeon YJ. Antioxidant activity and cell protective effect of loliolide isolated from Sargassum ringgoldianum subsp. coreanum. Algae. 2011;26:201-8. 